\title{
PEMANFAATAN ATRAKTAN NABATI UNTUK PENGENDALIAN \\ LALAT BUAH Bactrocera Sp PADA TAANAMAN \\ CABAI (Capsicum annum L.)
}

\author{
Yustina M.S.W. Pu' ${ }^{1}$, Fatmawati ${ }^{2}$ \\ Yus_puu@yahoo.com
}

\section{Program Studi Agroteknologi, Fakultas Pertanian, Universitas Flores}

\begin{abstract}
The research aimed to know the use of vegetable attractants for monitoring fruit flies (bactrocera sp) and to know the most effective attractant on trapping fruit flies ofchilli plant (Capsicum annum L).

Method used in this study was Randomized Block Design namely treatment without attractan (A0), Steiner + guava attractan (A1), steiner + custard apple attractan (A2), steiner + banana attractan (A3), steiner + papaya attractan (A4). The variable are population of fruit flies, the number of rotten fruit, and rotten intensity of fruit.

The result showed that the use of vegetable attractan is effective in monitoring fruit flies pest, in which population of fruit flies pest was trapped about $27.74 \%$, number of rotten fruit is $23,38 \%$ and rotten intensity is $18,64 \%$. Custard apple attractan gave the highest influence towards all observation variables.
\end{abstract}

Keywords: attractan, vegetable, fruit flies

\section{PENDAHULUAN}

Lalat buah merupakan salah satu hama yang menyerang berbagai buah di Indonesia. Hama ini dapat menurunkan populasi produksi baik dari segi kuantitas maupun kualitas. Gejala serangan akibat lalat buah ditemukan terutama pada buah, biasanya terdapat lubang kecil dibagian tengah kulitnya. Serangan lalat buah ditemukan pada buah yang hampir masak. Gejala awal ditandai dengan noda/bintik, bekas tusukan ovipositor (alat peletak telur) lalat betina saat meletakkan telur ke dalam buah. Kehilangan hasil akibat serangan lalat buah di Indonesia cukup besar. Hal ini disebabkan karena stadia yang merusak adalah larva yang menyerang langsung pada buah tanaman. Jenis lalat buah yang banyak terdapat di Indonesia adalah dari genus Bactrocera dan salah satu jenis yang 
Yustina: pemanfaatan atraktan nabati untuk pengendalian lalat buah bactrocera sp pada taanaman cabai (Capsicum annum L.)

sangat penting dan genus adalah Bactrocera $\mathrm{Sp}$ merupakan lalat buah yang bersifat polifag (Banyak inang), mempunyai sekitar 26 jenis inang seperti belimbing, jambu biji, tomat, cabai merah, melon, apel, srikaya, nangka kuning,mangga, dan jambu air.

Salah satu usaha pengendalian yang ramah bagi lingkungan dan cukup efektif dalam menekan populasi lalat buah yaitu dengan menggunakan atraktan beberapa jenis atraktan, untuk mengendalikan hama lalat buah seperti atraktan dari ekstrak srikaya, jambu biji, pepaya dan mangga. Jenis-jenis buah ini selain sebagai sumber vitamin juga mengandung aroma yang sangat baik menyengat dan sebagaai bahan pestisida nabati, buah ini juga bisa digunakan sebagaai atraktan untuk mengurangi seranggan akibat lalat buah.

Zat atraktan ini dapat mengacaukan perilaku kawin lalat buah dan merupakan suatu alternatif efektifitasnya dilapangan.Zat penarik (attractance) ialah suatu zat yang menarik serangga menuju ke arah sumber zat itu. Sumber zat penarik terdapat pada serangga, burung, hewan menyusui, tumbuh-tumbuhan segar dan tumbuhtumbuhan yang telah membusuk. Hasil penelitian dari beberapa jenis atraktan menunjukkan bahwa jumlah lalat buah yang ditangkap berbeda nyata untuk masingmasing perangkap, perangkap dengan menggunakan ekstak srikaya dapat menangkap hama lalat buah sebanyak 40 ekor/hari.

Berdasarkan pernyataan yang disebutkan di atas, maka peneliti melakukan penelitian ini dengan tujuan untuk mengetahui pemanfaatan atraktan nabati untuk pengendalian lalat buah (Bactrocera sp) dan untuk mengetahui atraktan apa yang paling efektif dalam menangkap lalat buah pada tanamann cabai (Capsicum annum $\mathrm{L}$ ).

\section{METODE PENELITIAN}

Penelitian dilakukan di kebun Percobaan Fakultas. Pertanian Universitas Flores Desa Lokoboko, Kecamatan Ndona, Kabupaten Ende dengan Ketinggian Tempat 500 mdpl, curah hujan rata-rata $1.508-2.750$ $\mathrm{mm} /$ tahun, suhu $27,45 \%$ (Dinas Pertanian Kabupaten Ende). Penelitian ini dilaksanakan pads bulan Juni sampai Agustus 2013. Adapun bahan yang digunakan dalam penelitan ini adalah: sari buah Srikaya, Jambu Biji, Pepaya, Mangga, gulungan kapas, bekas botol air mineral, kawat, kayu penopang 
Yustina: pemanfaatan atraktan nabati untuk pengendalian lalat buah bactrocera sp pada taanaman cabai (Capsicum annum L.)

perangkap, Pagan Perlakuaan. Adapun alat yang digunakan dalam penelitian ini adalah cangkul, parang, pilau, alat tulis, kertas HVS, pagan LJK clan kamera.

\section{Rancangan Penelitian}

Rancangan yang digunakan dalam percobaan ini ialah rancang acak kelompok (RAK) yang terdiri dari 5 perlakuan dan 4 ulangan yaitu:

A0 : Kontrol (tanpa atraktan)

$\mathrm{Al}$ : Perangkap steiner + Atraktan

Jambu Biji Merah

A2 : Perangkap steiner + Atraktan

Srikaya

A3 : Perangkap steiner + Atraktan

Mangga

A4 : Perangkap steiner + Atraktan

Pepaya

\section{Persemaian}

Media yang digunakan adalah tanah yang banyak mengandung humus dan ditambahkaan pupuk kandang ayam, media dari tanah dan pupuk kandang dicampuur secara merata, lalu diisi pada kotak persemaian yang sudah disiapakan. Media semai disiramkan dengan air sampai basah , lalu benih ditabur pada media semai, media semai disiram setiap hari agar kelembaaban terjaga dengan baik, kemudian media ditempatkan padaa tempat yang teduh tetapi bukan tertutup secara penuh, dimana media pembibitan hares mendapatkan sinar matahari

\section{Pembibitan}

Benih yang telah berkecambah atau bibit cabai umur 10-14 hari (biasanya telah tumbuh sepasang daun) sudah dapat dipindahkan ke tempat pembibitan.Siapkan tempat pembibitan berupa polybag ukuran $8 \times 9 \mathrm{dm}$ atau bumbungan dari bahan daun pisang sehingga lebih murah harganya. Masukkan ke dalamnya campuran tanah, pasir dan pupuk kandang. Pindahkan hibit cabai ke wadah pembibitan dengan hati-hati.Pada saat bibit ditanam di bumbungan, tanah di sekitar akar tanaman ditekan-tekan agar sedikit padat dan bibit berdiri tegak.Letakkan bibit ditempat teduh dan sirami secukupnya untuk menjaga kelembabannya. Pembibitan ini bertujuan untuk meningkatkan daya adaptasi dan daya tumbuh bibit pads saat pemindahan ke tempat terbuka di lapanan. Pemindahan bibit ke lapangan dilakukan setelah bibit cabai berumur 1/2 sampai satu bulan atau telah berdaun $5-7$ helai.

\section{Persiapan Lahan}

Lahan yang akan digunakan untuk penelitian diolah dengan menggunakan 
Yustina: pemanfaatan atraktan nabati untuk pengendalian lalat buah bactrocera sp pada taanaman cabai (Capsicum annum L.)

cangkul dengan kedalaman olah tanah 15-20 cm. Pengolahan dilakukan hingga tanah menjadi gembur, rata dan bersih dari sisa-sisa gulma dan perakaran. Petakpetak percobaan dibuat bedengan dengan ukuran $200 \mathrm{~cm} \quad$ x $300 \mathrm{~cm}$ denganpembatas parit di sekeliling Lahan yang digunakan sebagai tempat penelitiandengan lebar $30 \mathrm{~cm}$ dan kedalaman25 $\mathrm{cm}$ yang berfungsi sebagai saluran drainase. Jarak antar petak ulangan $150 \mathrm{~cm}$, jarak antara petak perlakuan $100 \mathrm{~cm}$.

\section{Pemupukan}

Setelah bedengan dibuat selanjutnya dilakukan kegiatan pemupukan, pemupukan dilberi satu minggu sebelum penanaman dilakukan. Pupuk disebarkan secara merata pada setiap petak percobaan pupuk yang dipakai ialah pupuk kandang ayam.

Bibit cabai yang sudah berumur 30 hari, sudah siap ditanam, dengan jarak tanam $50 \mathrm{~cm}$ x $60 \mathrm{~cm}$ dengan setiap lubang tanam 1 anakan cabai, pemindahan dilakukan sore hari diatas jam 16.00. Setelah penanaman segera dilakukan penyiraman.

\section{Perniliharaan}

Dalam usaha pemeliharaan tanaman yang perlu dilakukan adalah penyiraman secara teratur untuk menjaga kelembaban tanah, pemupukan, pembersihan gulma disekitar areal tanaman sebaiknya dilakukan pada saat gulma masih muda. Pemasangan ajir dilakukan pada saat tanaman mulai berbunga sehingga dapat menjadi penopang atau penguat supaya tanaman dapat berdiri tegak.

\section{Pembuatan Perangkap}

Langkah pertama yang perlu di lakukan adalah menyiapkan bahanbahan yang diperlukan dalam pembuatan perangkap. perangkap botol bekas air mineral, botol yang telah tersedia dipotong pada bagian tutupannya kemudian tutup botol yang telah dipotong diberi lem pada sisi dalamnya agar ticlak mudah terlepas pada saat pengaplikasian, tutupan yang sudah diberi lem dipasang terbalik mirip corong agar lalat buah mudah untuk masuk kedalamnya dan sulit untuk keluar lagi, sehinga dapat berfugsi sebagai pintu masuk bagi lalat buah, kapas yang telah ditetesi dari beberapajenis anraktan dimasukan kedalam botol perangkap dengan menggunakan kawat dan digantung pada bagian tengah botol perangkap.

\section{Variabel Pengamatan}

Pengamatan dilaukan pada saat tanaman mulai berbuah sampai tanaman 
Yustina: pemanfaatan atraktan nabati untuk pengendalian lalat buah bactrocera sp pada taanaman cabai (Capsicum annum L.)

siap dipanen, pengamatan di lakukan setiap hari. Pengamatan terhadap parameter yang di amati antara lain sebagai berikut:

Populasi lalat buah yang tertangkap (ekor). Pengamatan terhadap jumlah populasi lalat buah dilakukan pada saat tanaman berumur 51 hari setelah tanam (hst) sampai pada tanaman berumur 65 hari setelah tanaam (hst). Dengan menghitung lalat buah yang terperangkap. Pengamatan didilakukaan tiga hari sekali dan dilakukan pada pagi hari.

1. Jumlah Buah Rusak

Jumlah buah yang tersererang dihitung dengan cara menghitung semua buah yang terserang (rusak) akibat serangan lalat buah dan dilakukan pada saat tanaman berbuah atau siap di panen.

2. Intensitas Kerusakan Intensitas kerusakan buah cabai di amati mulai satu minggu setelah pemasangan alat perangkap. Pengamatan di lakukan satu minggu sekali dengan menggunakan rumus:

$$
I=\frac{a}{a+b} \times 100 \%
$$

Dimana:I = Intensitas Serangan

$\mathrm{a}=$ Jumlah buah yang rusak

$\mathrm{b}=$ Jumlah buah keseluruhan

- Intensitas Serangan

1. Kerusakan > 50\% : Intensitas serangan sangat best

2. Kerusakan $30 \%$ - 50\%: Intensitas serangan berat

3. Kerusakan $15 \%-29 \%$ : Intensitas serangan cukup berat

4. Kerusakan 1 - 14\%: Intensitas serangan ringan

5. Kerusakan 0\% : Intensitas serangan tidak

\section{Analisis Data}

Data yang terkumpul sebelum dianalisis ditranformasi dengan transformasi $\operatorname{arcin} \sqrt{x}$. Untuk melihat tingkat nyata pengaruh perlakuan digunakan analisis sidik ragam dan apabila perlakuan menunjukan pengaruh yang sangat nyata, nyata maka dilanjutkan dengan uji BNT taraf 5\% (Gomez \& Gomez, 1995).

\section{Hasil dan Pembahasan}

Populasi Hama Lalat Buah yang Tertangkap (ekor) 
Yustina: pemanfaatan atraktan nabati untuk pengendalian lalat buah bactrocera sp pada taanaman cabai (Capsicum annum L.)

Tabel 4.1 Pemanfaatan atraktan nabati terhadap populasi hama lalat buah yang tertangkap.

\begin{tabular}{cc}
\hline Perlakuan & $\begin{array}{c}\text { Lalat } \\
\text { Tertangkap }\end{array}$ \\
\hline AO & $0 \mathrm{c}$ \\
$\mathrm{A} 1$ & $24,59 \mathrm{~b}$ \\
$\mathrm{~A} 2$ & $27,74 \mathrm{a}$ \\
$\mathrm{A} 3$ & $23,06 \mathrm{~b}$ \\
$\mathrm{~A} 4$ & $24,59 \mathrm{~b}$ \\
\hline BNT & 0,56 \\
\hline Keterangan: Angka-angka yang diikuti \\
huruf yang sama pada kolom yang \\
sama berbeda tidak nyata pada uji \\
BNT taraf 5\%. Data telan \\
ditransfonnasi menggunakan Arcsin
\end{tabular}

Hasil penelitan menunjukan bahwa pemanfaatan atraktan nabati memberikan pengaruh terhadap populasi hama lalat buah yang tertangkap (tabel 4.1). Perlakuan atraktan nabati yang digunakan berpengaruh nyata terhadap populasi hama lalat buah yang tertangkap, dimana perlakuan atraktan ekstrak srikaya (A2) sebesar 27,74 ekor, atraktan ekstrak pepaya (A4) sebesar 24,59 ekor, atraktan ekstrak jambu biji (A1) sebesar 24,59 ekor, atraktan ekstrak mangga (A3) sebesar 23,06 ekor dan tanpa perlakuan atraktan sebesar 0 ekor. Hasil ini menunjukan bahwa setiap atraktan yang digunakan dari setiap akstrak tersebut berpengaruh terhadap perilaku hama lalat buah akibat aroma yang ada pada setiap atraktan. Ketertarikan lalat buah terhadap aroma yang didikeluarkan oleh masingmasing ekstrak sangatlah tergantung pada kandungan zat atraktan yang terkandung masing-masing ekstrak dan jugs tergandung pada spesies lalat buah, hal ini yang menpengrui tangkaapan dari perangkap yang sudah diberi ekstrak untuk menarik lalat buah masuk kedaalam peangkap yang digunakan.

$$
\text { Hama lalat buah juga }
$$
menggunakan isyarat visual (visual cues) ataupun isyarat kimia (Chemical cues) untuk menemukan inang berupa buah atau pun sayuran. Keserasian isyarat visual akan menyebabkan lalat buah lebih tertarik untuk menemukan inangnya. Beberapa penelitian telah dilakukan aantara lain bentuk dan ukuran dari alat perangkap yang merupakan stimulasi visual serta memberikan tanggapan tertentu terhadap hams lalat buah. Isyarat kimia berupa bau yang dikeluarkan oleh buah maupaun atraaktan sintesis (parapheroman) akan menyebabkan lalat buah tertarik untuk mendekati bahan tersebut. Disamping itu walaupun tanaman inang hama lalat buah mempunyai kenopi yang lebih tinggi, namun karena lalat buah membentuk 
Yustina: pemanfaatan atraktan nabati untuk pengendalian lalat buah bactrocera sp pada taanaman cabai (Capsicum annum L.)

pupa dan keluar dalarn bentuk dewasa dari dalam tanah maaka perangkap yang digunakan untuk mengendalikan hama lalat buah jantan tidak perlu diletakaan sesuai dengan tingginya kenopi tanaman yang akan dikendalikan.

Jenis atraktan ekstrak srikaya menunjukan populasi hama lalat buah yang tertangkap paling tinggi sebesar 27,74 akor dibandingkan perlakuan yang lain. Hal ini disebabkan karena aroma atraktan srikaya yang sangat menyengat dengan kandungan skuamosin, asimisin, atherospermidine, lenuginosin, alkaloid tipe asporfin (anorain) dan retikulin, kandungan skuamosinnya berfungsi sebagai insektisida.

\section{Jumlah Buah Rusak (Buah)}

Hasil penelitian pemanfaatan atraktan nabati dalam pengendalian hama lalat buah terhadap jumlah buah cabai yang rusak menunjukan bahwa perlakuan atraktan yang berbeda tidak memberikan pengaruh yang nyata terhadap jumlah buah rusak (tabel 4.2)

Tabel 4.2 Pemanfaatan atraktan nabati terhadap jumlah buah rusak (Buah).

\begin{tabular}{cc}
\hline Perlakuan & Buah Rusak \\
\hline AO & $26,00 \mathrm{a}$ \\
A1 & $23,10 \mathrm{a}$ \\
A2 & $17,58 \mathrm{a}$ \\
A3 & $23,38 \mathrm{a}$ \\
A4 & $19,92 \mathrm{a}$ \\
\hline BNT & 13,15 \\
\hline
\end{tabular}

Keterangan: Angka -angka yang diikuti huruf yang sama pada kolom yang sama berbeda tidak nyata pad $\sqrt{x} \mathrm{ji}$ BNT taraf 5\%. Data telan ditransfonnasi menggunakan Arcsin

Perlakuan jumlah buah rusak yang tidak berbeda nyata pada setiap perlakuan disebabkan karena pada beberapa perlakuan, jumlah buah cabai yang dihasilkan sedikit, sehingga tidak memberikan pengaruh yang berbeda, walapun populasi lalat buah yang tertangkap paling tinggi pada perlakuan atraktan srikaya. Hasil buah yang tidak merata menyebabkan jumlah buah yang rusak tidak memberika perbedaan yang nyata.

\section{Intensitas Kerusakan}

Hasil penelitan menunjukan bahwa perlakuan atraktan ekstrak nabati yang berbeda menyebabkan perbedaan intensitas kerusakan yang ditimbulkan pada tanaman cabai. Dimana intensitas kerusakan buah cabai kontrol (tanpa perlakuan) (A0) sebesar 18,64\%, perlakuan atraktan ekstrak jambu biji (A1) sebesar $18,37 \%$, perlakuan 
Yustina: pemanfaatan atraktan nabati untuk pengendalian lalat buah bactrocera sp pada taanaman cabai (Capsicum annum L.)

atraktan ekstrak srikaya (A2) 16,60\%, perlakuan atraktan ekstrak mangga (A3) sebesar $17,10 \%$ dan perlakuan akstrak pepaya (A4) sebesar 18,01 \% (Tabel 4.3).

Tabel 4.3 Pemanfaatan Atraktan Nabati Terhadap Intensitas Kerusakan (\%)

\begin{tabular}{cc}
\hline Perlakuan & Intensitas Kerusakan \\
\hline $\mathrm{AO}$ & $18,64 \mathrm{a}$ \\
$\mathrm{A} 1$ & $18,37 \mathrm{a}$ \\
$\mathrm{A} 2$ & $16,60 \mathrm{~b}$ \\
$\mathrm{~A} 3$ & $17,10 \mathrm{~b}$ \\
$\mathrm{~A} 4$ & $18,01 \mathrm{a}$ \\
\hline $\mathrm{BNT}$ & 0,83
\end{tabular}

Keterangan: Angka -angka yang diikuti huruf yang sama pada kolom yang sama berbeda tidak nyata pad $\sqrt{x} \mathrm{ji}$ BNT taraf 5\%. Data telan ditransfonnasi menggunakan Arcsin

Perlakuan atraktan ekstrak srikaya menunjukan intensitas kerusakan buah cabai paling rendah yaitu $16,60 \%$ dibandingkan perlakuan lainnya. Hal ini disebabkan karena atraktan ekstrak srikaya menunjukan populasi hama lalat buah yang tertangkap paling tinggi dan jumlah buah rusak paling tinggi walaupun tidak berbeda nyata dengan perlakuan lainnya.

Penggunaan atraktan yang tidak sesuai juga sangat mempengarui hasil tangkapan dari perangkap yang dipasang, dimana aroma yang dikeluarkan dari ekstrak yang mengakibatkan lalat buah jantan lebih mendekati atraktanya dari pada lalat buah betina itu sendiri sehingga aroma yang dikeluarkan dapat smengacaukan perkawinan lalat buah. Akibat karena tedadi perkawinan lalat buah betina tidak dapat meletakkan telur pada tanaman cabaai, hal ini juga berpengaruh dengan persentase kerusakan buah (Katsoyannos \& Koulousis)

Pada kontrol (tanpa perlakuan) memberikan intensitas kerusakan yang paling tinggi sebesar $18,64 \%$. Hal ini disebabkan karena tidak adanya perangkap atraktan yang digunakan untuk menarik lalat, sehingga terjadi perkawinan antara lalat jantan dan betina yang menyebabkan jumlah buah rusak dan intensitas kerusakan tinggi.

\section{Kesimpulan}

Berdasarkan hasil penelitian dapat disimpulkan bahwa:

1. Tingkat keefektifan dari penggunaan jenis atraktan berbeda-beda, jenis atraktan tanpa perlakuan (0),perankap steiner dan antraktan srikaya $(27,74)$, perangkap steiner dan atraktan jambu biji merah $(24,59)$, perangkap steiner dan atraktan mangga (23,06), dan perangkap steiner dan atraktan pepaya $(24,59)$.

2. Perangkap steiner dan atraktan 
Yustina: pemanfaatan atraktan nabati untuk pengendalian lalat buah bactrocera sp pada taanaman cabai (Capsicum annum L.)

srikaya yang terbaik untuk menarik/menangkap lalat buah ke dalam perangkaap dengan tingkat keefektifanya menangkap lalat buah sebanyak 27,74 .

\section{UCAPAN TERIMA KASIH}

Pada kesempatan ini penulis ingin mengucapkan terima kasih kepada semua pihak yang telah membantu dengan caranya masing-masing dalam melengkapi tulisan ini.

\section{DAFTAR PUSTAKA}

Agus Kardinan. (2001). Pestisida Nabati, Ramuan Nabati dan Aplikasi.Jakarta: Penebar Swadaya.

Alexander, B. H., M. Beroza, T. A. Oda, L. F. Steiner, D. H. Miyashita, and W. C. Mitchell. 1962. The development of male melon fly attractants. J. Agric. and Food Chem. 10: 270-276.

Alyoklin, A.V. R.H. Messingand J.J.Dian. 2000. Visual andolf' stimul and fruit maturity affect trap captures of oriental fruit flies (Diptera: Tephritidae). J Econ. Entomol. 93 (3): 664-649.

Aluja, M., M. Cabrera, J. Guillen, H. Celedonio, and F. Ayora.1989. Behavior of

Anastrepha ludens, A. oblique and A. serpentine (Diptera: Tephritidae) on a wild mango tree (Mangifera indica) harboring tree McPhail traps. Insect S6.Applic. 10: 309318.

Anonimous. 2009.Budidaya Cabai. http://insideevvinme.blokspot.com /2007/Ull/ Budidaya-cabai.

Anonimous.2009. Dinar Pertanian
Tanaman Pangan dan

Peternakan. Produksi Cabai Dalam Negeri. 08/10/2011.

Bateman, 1972.The Ecology of Fruit Flies.Ann. Rev. Entomol., 17: $493-519$.

Bero7n, M., N. Green, S. I. Gertler, L. F. Steiner, and D. H. Miyashita. 1961. Insect attractants: new attractants for the Mediterranean fruit fly. J.Agric. Food Chem. 9: 361-365.

Burditt, A. K. 1982. Anastrepha suspensor (Loewy (Diptera: Tephritidae), McPhail Ttraps for survey and detection.Florida Entomol. 65: 367-373.

Christenson, L.C. and R.H. Foote. 1960. Biology offruit flies. Ann. Rev. Entomol. 5: 171-192. (Prokopy \& Economopoulos 1976; Vargas \& Nishida 1985).

Gomez, K.A. Gomez, A.A. 1995. Prosedur Statistik Untuk Penelitian Pertanian. Universitas Indonesia. Jakarta.

http://creatures.ifos.ulfedu/fruit/trofical/ oriental-fn-iit-fly.htm.

Kanisius.1997. Hama Lalat Buah dan Pengendaliannya. Anggota HAP. Yogyakarta.

Kanisius. 1989. Hama dan Penyakit Tanaman. Anggota EKAPI. Yogyakarta (2003).Tanaman Pengendali Lalat Buah. Jakarta: Agro Media Pustaka.

Nugroho, S.P. (1997). Hama Lalat Buah dan Pengendaliannya Yogyakarta: Kanisius.

Saga Kalie.(1992). Mengatasi Buah Rontoh, Busak dan Berulat.Jakarta: Penebar Swadaya.

Weems, J.13 Heppner, dan James L. Nation. (1999). Pengendalian Lalat Buah.University of Florida. 